\title{
La metapsicología histórica
}

RESUMEN: "S. Freud comenzó en 1900 una argumentación de la que resuelve asociar su conflicto infantil a una tragedia griega y D. Anzieu amplió su labor en 1966. Pero J. P. Vernant muestra, sobre el texto Edipo rey y con los datos de la antropología, como, uno y otro, leídos fielmente, se contradicen. Teniendo en cuenta que el propio texto de Sófocles trata sobre el enigma, se toma también el discurso del antropólogo junto a los datos del psicoanálisis".

PALABRAS CLAVE: "Edipo rey", "Psicoanálisis", "Antropología".
ABSTRACT: "S. Freud began in 1900 an argumentation about the association of his infantile conflict with a Greek tragedy and D. Anzieu has enlarged it in 1966. But J. P. Vernant shows, on the same text Edipe king and with the documents of the anthropology, that, both, in their own way, are in contradiction. Text of Sofocles talks about the riddle so we take the reasoning of the anthropologue at hand of the psichoanalitics documents".

KEYWORDS: "Edipe king", "Psichoanalise", "Anthropology".

\section{Juicio del más importante episodio del "Edipo rey"}

"Mi padre era Pólibo, corintio, y mi madre Mérope, doria. Era considerado yo como el más importante de los ciudadanos de allí hasta que me sobrevino el siguiente suceso, digno de admirar, pero, sin embargo, no proporcionado al ardor que puse en ello. He aquí que en un banquete, un hombre saturado de bebida, refiriéndose a mí, dice, en plena embriaguez, que yo era un falso hijo de mi padre." (1)

El análisis de este fragmento cierra, según J. P. Vernant, las opciones del psicoanálisis que se embarca en la aventura de la mitología por el arco del triunfo del mito de Edipo, desde que Freud lo incorpora a su marcha, señalando allí la presencia del triplete siguiente; enamoramiento de la madre, deseos parricidas y castración, como figura autónoma en La interpretación de los sueños de 1900.

“¿Por qué, se dirá, ha introducido Sófocles este episodio? ¿No es para sugerir que en el fondo de sí mismo Edipo sabe ya que sus padres no son los que pasan por tales, pero que se niega a confesárselo para ceder mejor a su fantasma de incesto y parricidio. (...) las razones de Sófocles son extrañas a la psicología profunda. Responden a otros órdenes de necesidad. Estética, en primer lugar. 
El descubrimiento del verdadero origen de Edipo no podía aparecer como una revelación repentina e inesperada, un vuelco imprevisible de la situación. Debe ser preparada psicológica y dramáticamente. La alusión de Edipo a este incidente de su juventud, (...) es un elemento indispensable en esta preparación.

Necesidad religiosa luego. En la tragedia el oráculo es siempre enigmático, jamás mentiroso. No engaña jamás, da al hombre la ocasión de errar. Si el dios de Delfos hubiera efectuado su predicción sin que éste tuviera la menor razón para interrogarse por su origen, sería culpable de haberle engañado deliberadamente, le habría expulsado de Corinto, le habría arrojado sobre la ruta de Tebas hacia el incesto y el asesinato." (2)

Si embargo, la justificación de la adopción de Edipo en 1900 no recibió tanta atención como las muestras de alegría por el hallazgo, y la demostración psicoanalítica de la relación entre la obra griega con ese conflicto infantil de la clínica se da, allí al menos, por evidente en sí misma.

No es, en consecuencia, un argumento de Freud el que responden aquí desde la antropología sino a uno escrito 66 años después por uno de sus seguidores, el psicoanalista francés D. Anzieu, quien amplía aquella escueta comunicación de su maestro sobre el particular con ciertas proposiciones que, considera, se derivan directamente de la teoría. El argumento es suyo literalmente aunque se asume que, virtualmente, pertenece a Freud.

“... (p) Para que esta lectura esté fundamentada hay que admitir con Anzieu que Edipo sabe pertinentemente que Mérope y Pólibo, soberanos de Corinto que le han educado como a su hijo, no son ni su padre ni su madre, sino simples padres adoptivos. Ahora bien, a lo largo de toda la pieza, hasta que se revela la verdad, Edipo está persuadido de lo contrario. No una sino muchas veces, Edipo se confiesa sin la menor duda hijo de Mérope y de Pólibo.” (3)

Implicación de necesidad para toda interpretación psicoanalítica que, precisamente, tiene en este episodio a su mejor valedor. Que no se encuentra otro en que se defienda mejor esa afirmación general, esa implicación de cuyo cumplimiento depende el destino de la explicación en su conjunto. Así lo considera Anzieu y así Vernant quien replica sobre la letra de aquellas mismas palabras la conclusión de su compatriota y sus bases.

“¿En qué se funda Anzieu para hacer decir así al texto lo contrario de lo que enuncia con tanta claridad? (...), convirtiéndonos en abogado del diablo, podríamos argumentar con un pasaje que, interpretado en términos de psicología profunda, vendría a apuntalar su tesis y a cuestionar la sinceridad de las afirmaciones de Edipo en cuanto a su origen. Se trata de los versos 774-793. (...) en el curso de un festín, un borracho le insulta llamándole "hijo putativo"." (4) 


\section{Anzieu y la desmesura.}

No, el error de Edipo que pretende estar poniendo a salvo a sus padres de sí mismo al huir de Corinto, a pesar de que el oráculo le advierte y que no tiene prudencia suficiente para saber que no de los verdaderos, se debe no a que en el fondo de sí mismo conozca el verdadero origen de su linaje y por ello marche sobre Tebas sino a que su carácter es sustancialmente orgulloso; tanto que confía excesivamente en su juicio. Este es el extremo donde tiene lugar el error pues aquí se juzga la palabra de Apolo.

"Pero, a la pregunta de Edipo: ¿Pólibo y Mérope son mis padres?, Apolo no responde nada. Adelanta sólo una predicción: "Te acostarás con tu madre, matarás a tu padre", y esta predicción, en su horror, deja abierta la cuestión planteada. Es, por tanto, Edipo el que comete la falta de no inquietarse por el silencio del dios y de interpretar su palabra como si le aportase la respuesta al problema de su origen. Este error de Edipo procede de dos rasgos de su carácter: demasiado seguro de sí, demasiado confiado en su gnóme, su juicio ...” (5).

Y en la disputa que, después de la consulta con el adivino Tiresias que le acusa del asesinato de Layo, mantiene con su cuñado Creonte el rey Edipo que quiere ver, conciliando la acusación pública con el supuesto indudable de su inocencia, un apaño secreto entre uno y otro para sacarle del trono, como acaso hicieran con el antiguo rey. Esta relación quiere ser puesta al lado de la temática incestuosa mientras que es por referencia a este rasgo de la personalidad de Edipo por lo que se entiende.

“(P) proyectando sobre Creonte su propio deseo de poder, se convence en una misma instancia de que su cuñado, animado por el phtónos -la envidia respecto a los grandes-, trata de ocupar su lugar ..." (6)

Y nunca que más allá del derecho sobre el trono de Tebas, la disputa gira en torno al derecho sobre la reina.

“"La vinculación incestuosa entre Creonte y Yocasta, los celos de Edipo hacia el hermano de su mujer y madre es una hipótesis necesaria para terminar de hacer comprensible el drama de Edipo". La hipótesis es necesaria, indudablemente, no para comprender el drama, sino para hacerlo entrar en el marco de una interpretación preestablecida. No hay el menor rasgo de una vinculación incestuosa entre el hermano y la hermana. (...). Creonte está celoso de él, no en el sentido erótico del término, sino en el social, como lo indica la palabra griega empleada: phthónos significa envidia respecto a aquel que es más rico, más poderoso, más astuto. La rivalidad (...) se sitúa enteramente en el terreno de una competición por el poder. A los ojos de Edipo, Creonte no puede soportar su victoria sobre la Esfinge, su popularidad, su soberanía.” (7). 
Con respecto al resto de las novedades que añade Anzieu a la lectura psicoanalítica el resultado de la acción antropológica es idéntico. Como en este caso se enfrenta a una derivación teórica de la síntesis inicial de 1900. Cada una de esas nuevas proposiciones se presenta como necesaria, esto es, no puede no ser comprobada en el texto. Vernant considera, como se ve, también desacertada la intervención sobre toda esta serie de puntos, los más importantes de los cuales se refieren a la calificación de las relaciones de Edipo con las más altas dignidades del reino.

"La unión conyugal que los tebanos le ofrecen con su reina no puede significar para Edipo una reposesión de la madre, porque Yocasta es para él una extraña, una kséne (...). Se dirá que Yocasta es "un sustituto" de Mérope y que Edipo vive sus relaciones conyugales con la reina de Tebas al modo de una unión con su madre. Todo está denunciando la falsedad de esta interpretación. Si Sófocles la hubiera querido, fácil le habría sido sugerirla. (...). Unas relaciones de tipo edípico, en el sentido moderno del término, entre Edipo y Yocasta, habrían ido directamente contra la intención trágica de la pieza, centrada sobre el tema del poder absoluto de Edipo y de la hýbris que necesariamente se desprende de ella." (8).

De modo que, Anzieu y, por ende, Freud en su día, ignoran que el verdadero tema de la tragedia es lo que los griegos llamaban hýbris, la desmesura en que acaba desembocando necesariamente el poder absoluto del tirano. Es la única clave que abre todas y cada una de las puertas del texto. Desviados de esta línea interpretativa, caen necesariamente en el acomodo artificial del texto a sus teorías. El resultado final es la obra deformada.

"Pero veamos por qué procedimientos el psicoanalista fuerza el material legendario a plegarse a las exigencias del modelo que, antes incluso de abordar su estudio, llevaba en sí, como un mago posee la verdad." (9)

\section{Del fundamento de toda crítica al psicoanálisis.}

El resultado, en efecto, es testigo del proceso llevado por Freud y seguidores al tiempo. Lo caracteriza de principio a fin. Nunca hacen más que enunciar su tesis y demostrarla tan escuetamente como se ha visto.

"En efecto, la interpretación del mito y del drama griego no parece constituir a sus ojos problema de ningún tipo. No tienen que ser descifrados por métodos de análisis apropiados. Legibles inmediatamente, completamente transparentes para el espíritu del psiquiatra, ofrecen de entrada una significación cuya evidencia aporta a las teorías psicológicas del clínico una garantía de validez universal." (10). 
La principal queja o, si se quiere, el fundamento o la causa de todas ellas, es que el psicoanálisis no conoce suficientemente la amplitud del territorio sobre el que pretende establecer su imperio. Como no sabe de los mitos, sus versiones, las fuentes y mucho menos las condiciones sociales que los determinan a ellos y a sus modos de expresión, es normal que incurra en errores tanto en esas tesis como en sus demostraciones.

"A este respecto podría proponerse a los psicoanalistas que se convirtieran más en historiadores ...” (11)

La cantidad de conocimientos, de datos que estos estudiosos no manejan no es tan grave como la inexistencia de un método. La solución de este problema podría haber sido, por su subordinación, la de ese primero.

“(h) Habría sido preciso que la hipótesis freudiana, en lugar de presentarse en el punto de partida como una interpretación evidente y que se impone por su propia entidad, apareciese al término de un minucioso trabajo de análisis como una exigencia impuesta por la obra misma, o una condición de inteligibilidad de su ordenación dramática, como el instrumento de un total desciframiento del texto." (12)

El conocimiento restringido, de dominios restringidos, produce tesis restringidas $\mathrm{y}$, por tanto, la aparición de la justa medida de los elementos a examen o la ampliación del horizonte considerado implica, frecuentemente, de eso se encarga Vernant, la cancelación inmediata de las proposiciones en juego por cuestiones meramente técnicas.

No hay términos medios entre el texto de Sófocles y la interpretación psicoanalítica. Ni términos medios ni un cuadro breve de las indicaciones que haya que seguir para pasar de uno a otra.

"Pero ¿dónde se sitúa ese "sentido" que se revelaría tan directamente a Freud y, tras él, a todos los psicoanalistas, como si, nuevos Tiresias, les hubiera sido otorgado el don de la profecía para alcanzar, más allá de las formas de expresión mítica o literarias, una verdad invisible al profano? Este sentido no es el que buscan el helenista y el historiador, un sentido presente en sus estructuras, que debemos reconstruir laboriosamente por un estudio de todos los planos del mensaje que constituye un relato legendario o una ficción trágica.” (13)

\section{La interpretación del efecto trágico.}

Este análisis de las opciones de supervivencia de la interpretación psicoanalítica en tierra del rey Edipo destruye la idea de que dentro del texto que se toma en cuenta se encuentra, por mucho que lo parezca, la figura que Freud busca resaltar. Pero Vernant no deja cabos sueltos, ni aunque se admita, y allí se viera, el análisis de las relaciones con su 
contexto desmiente también esta hipótesis ya descartada de antemano. No es, pero si fuese, fuera no sería. Esa figura, pues, no existe más que dentro del psicoanálisis.

“"La leyenda de Edipo es la reacción de nuestra imaginación contra esos dos sueños típicos, y como esos dos sueños van acompañados en el adulto de sentimientos de repulsión, es preciso que la leyenda comporte el espanto y la autopunición en su contenido mismo". Podríamos apostillar críticamente este es preciso y observar, por ejemplo, que en las versiones primitivas del mito no hay, (...) la menor huella de autopunición, puesto que Edipo muere pacíficamente instalado en trono de Tebas, (...). Es precisamente Sófocles quien, por las necesidades del género, da al mito su versión propiamente trágica, la única que Freud, que no es mitólogo, ha podido conocer..." (14).

Freud desconoce que en antiguas versiones del mito el elemento esencial de la castración está ausente. Aunque la antropología aceptase la presencia y la importancia de la figura del conflicto infantil en la tragedia "Edipo rey" no podría mantenerse en esa convicción por mucho tiempo. En cuanto salga del texto de Sófocles se desmoronará.

Porque, además, si el encuentro con dicha figura y la ponderación de su importancia han de hacernos afirmar, como a Freud en 1900, que se trata de la semilla oculta del observado, siempre, efecto trágico; ¿qué ocurre para el resto de las tragedias en las cuales no está presente esta unidad, no está sembrada la semilla de ese material, al tiempo que siguen ofreciendo a la vista el árbol, su efecto trágico?. Enseguida habrá que negar que el conflicto fuera su germen, señala Vernant.

“¿Cómo puede olvidar Freud que existen otras muchas tragedias distintas a Edipo rey y que (...) casi ninguna de ellas tiene nada que ver con los sueños edípicos? ¿hay que decir que son piezas detestables, que no comportan efecto trágico?" (15).

\section{Método de la psicología histórica.}

El desconocimiento del gran conjunto de factores que afectan el estudio de al antropología, que determina los fenómenos de la cultura griega del siglo $\mathrm{V}$, fuerza al psicoanálisis a precipitarse al error. Lo que desconoce del mito, aquello que puede decirse del texto trágico de Edipo, como todo y como partes, es desatendido. La definición de los elementos presentes en una obra como esa no ha de tenerse en cuenta desde lo que significan para nosotros sino de la relación con el resto de componentes de la cultura a la que pertenecen.

"El material de la tragedia ya no es entonces el sueño, planteado como una realidad humana extraña a la historia, sino el pensamiento social propio de la 
ciudad del siglo $\mathrm{V}$, con las tensiones y contradicciones que nacen en ella cuando surge el derecho y las instituciones de la vida política cuestionan, en el plano religioso y moral, los antiguos valores tradicionales." (16)

Los tres pilares que edifican el complejo infantil y que Freud cree ver en el mito, pues, no son más que ilusiones. Cuando nombra los correlatos de esos tres dentro del mito sólo estará haciendo referencia a ellos sin saber lo que son, los elementos del mito con que juega Freud dicen mucho más, no son los que cree que son. Los nombra, sí, los señala y ve en el texto, también; pero la asociación por semejanza de esos con cualquier otra cosa ha de hacerse por medio de su significado y como los define la antropología no es como el vienés.

“Captamos aquí, en vivo, la diferencia de método y de orientación entre la perspectiva freudiana por un lado, y la psicología histórica, por otro. Freud parte de una vivencia íntima, la del público, no situada históricamente; el sentido atribuido a esa vivencia es proyectado luego sobre la obra independientemente de su contexto sociocultural. La psicología histórica procede de forma inversa (...) la estudia según todas las dimensiones que comporta un análisis apropiado a este tipo particular de creación, desemboca en cada plano del estudio sobre un problema más vasto; el del contexto -histórico, social, mental- que confiere al texto todo su peso de significación. Una vez acabado este trabajo (...) [estará en condiciones de] definir en ellos el efecto trágico.” (17)

Por lo que a la antropología respecta los tópicos y episodios de la cultura griega de que hace uso Freud están vacíos de contenido o no llenos en la medida que les corresponde. Las asociaciones de la antropología sí tienen en cuenta el contenido significativo al completo. Incluyendo todos esos datos se descubre la importancia de las circunstancias sociopolíticas en que se origina la tragedia como su fuente de inspiración primera y su referencia significativa última.

"En la perspectiva de Freud, este carácter histórico de la tragedia resulta enteramente incomprensible."(18).

\section{Algunos productos de la psicología histérica.}

$\mathrm{Y}$, una vez se comprueba que el tema de la tragedia, la hýbris o desmesura derivada necesariamente del poder absoluto, personificada en Edipo, es la síntesis de la reflexión social del momento, movilizada en contra de los valores tradicionales, contra la pasada forma social, se descubre que la desvinculación del pasado es la contrapartida de la aparición, en la conciencia colectiva, de una nueva posición de lo humano frente a las fuerzas naturales. La delimitación progresiva de lo que hoy en día es la categoría de la voluntad. 
"El brusco surgimiento del género trágico a finales del siglo VI, en el momento mismo en el que el derecho comienza a elaborar la noción de responsabilidad, (...). Esta experiencia, todavía fluctuante e insegura, de lo que será en la historia psicológica de Occidente la categoría de la voluntad (...): ¿en qué medida es realmente el hombre la fuente de sus acciones? Incluso cuando parece tomar la iniciativa de ellos y cargar con la responsabilidad, ¿no tienen su verdadero origen en algo distinto a él?" (19)

Pero, he aquí el psicoanálisis de los primeros años y sobre qué asuntos dice estar ocupado.

"En líneas generales la histeria debe a este salir a la luz la voluntad contraria el sesgo demoníaco que tan a menudo presenta, rasgo que se exterioriza en no poder los enfermos hacer algo justamente en el momento y el lugar en que más lo ansiarían, en hacer justamente lo contrario de lo que se les ha pedido, y verse obligados a denotar lo que les es más caro y a ponerlo bajo sospecha (...) que durante un tiempo quedan sin remedio, a merced de sus representaciones contrastantes. (...) (s) Se presenta aquí una perversión de la voluntad; y (...) el asombro y el enojo a raíz de esa bi-escisión ininteligible para la enferma." (20)

La forma final, acabada, de la antropología respecto a su objeto resulta aparecer en el primer psicoanálisis. Aquí no es su forma final sino casi como el material de investigación. Pues esa supuesta reflexión sobre la voluntad está destinada a terminar siendo explicada por conceptos como el de inconsciente, solución teórica en la que, según estos teóricos, encuentran mejor acomodo la mayoría de los problemas que plantea. Pero hasta incluso de esos últimos conceptos se acaban encontrando ecos, de modo que a veces parece que, como antes, Vernant -e incluso Sófocles- hablan al modo de Freud.

"Pero en Edipo Rey la ruta entera está aun por recorrer. Edipo no conoce esa parte sombría que lleva en sí como siniestro reflejo de su gloria. Por eso no puede "entender" el silencio ambiguo del oráculo." (21)

"CORIFEO.- No tiene nada de extraño que en estos sufrimientos te lamentes y soportes males dobles." (22)

Una investigación de detalle sobre la primera de las coincidencias demuestra que no lo es. Porque no es, como se dijo, la síntesis sobre la reflexión trágica resumida en el desenvolvimiento de la categoría de la voluntad el final en la antropología y el principio en el psicoanálisis, sino lo mismo en ambas. Esta diferencia se disuelve, como sin querer, cuando pierde su sentido el desacuerdo fundamental entre Vernant y Freud, esto es, en palabras del primero, la divergencia de sus metodologías. 


\section{La convergencia en la metapsicología histórica.}

Un poco más atrás había dejado -Freud-, acelerado por la idea de la enorme magnitud del descubrimiento, volar su imaginación y, desatendiendo un método histórico, se apresura a deformar el mito llegando pronto al encuentro de una conclusión favorable. Mas, ¿no ha, como se afirma, tenido en cuenta el pensamiento social y las condiciones históricas?

"El $1^{\circ}$ de mayo de 1889 comencé a prestar atención médica a una dama de unos cuarenta años (...). Acerca de sus circunstancias de vida averiguo lo siguiente: $\mathrm{Su}$ familia es oriunda de Alemania central; desde hace dos generaciones se ha establecido en las provincias rusas del Báltico, haciendo allí considerable fortuna. (...). A los veintitrés años se casó con un hombre muy talentoso y capaz, quien, como gran industrial, se había labrado una posición descollante, pero era mucho mayor que ella. Desde hace unos meses la aquejan graves padecimientos; desazonada e insomne, es martirizada por dolores [etc., etc., etc. ]...” (23)

Aquí hay, en cambio, una muestra de todo lo contrario. El discurso freudiano tiene como objeto el contexto sociocultural de su paciente, y cómo elabora éste en términos de ese contexto, presente y pasado, su naturaleza, por así decir, mítica. La que ahora constituye es una historia de síntomas, un problema.

El uso de la voluntad en el panorama de los primeros escritos psicoanalíticos no es punto de partida de la investigación sino síntesis del modo en que los mismos pacientes vivían sus relaciones con el síntoma, sea cual fuera éste y aquéllas, no dejándolo de ser a la vez. Resumen de lo que de común hay en todas ellas y un ejemplo de esa observación histórica que ya no puede ser echada en falta.

La satisfacción de la condición de observación histórica no deja de alejar a estos dos distintos universos teóricos. Las palabras con que decía Vernant condiciones políticas o contexto histórico no se referían tal vez, se objetará, a lo que son esas realidades para, en este caso, los pacientes de nuestra modernidad. Que el hecho de que Freud examine el envoltorio social de sus pacientes no equivale a que lo haya hecho con la polis del siglo V. Por tanto;

“...una obra literaria que pertenece a la cultura de la Atenas del siglo V antes de Cristo y que traspone en sí misma de forma muy libre una leyenda tebana más antigua, anterior al régimen de la ciudad, ¿puede confirmar en algo las observaciones de un médico de principios del siglo XX sobre los pacientes que frecuentan su consulta?" (24)

Así que el ejercicio anterior que llamaba examen de las condiciones políticas a la mirada y estudio de la situación personal, contexto y referencia de lo social en 
el caso clínico, es una tergiversación de lo que Vernant tiene en cuenta como ese envoltorio socio-político.

VIII. Últimas condiciones de convergencia.

Sólo otra condición salva otro aspecto de esta objeción, construida, edificada sobre la distancia que se señala entre la política individual de un paciente freudiano y la colectiva de la polis del siglo V; distintas en cuanto al número.

"Si uno toma a la humanidad como un todo y la pone en lugar del individuo humano aislado, halla que también ella ha desarrollado formaciones delirantes inasequibles ..." (25)

Menudo, entonces, cambio de suertes. Las tesis que mejor explicaban, desde la antropología, la contradicción de las freudianas son las que ahora mejor las afirman y confirman a la vez que a ellas mismas que las negaban o no las contemplaban. ¿Cómo podrán seguir negándolas a la vez que las afirman, es decir, a la vez que se niegan a sí mismas?

“"La punta de la sabiduría se vuelve contra los sabios; la sabiduría es un crimen contra la naturaleza"." (26)

Ahora también el tema mismo de las distintas teorías sobre la tragedia es el mismo que el de esa tragedia. La contradicción y su contrario; ambos filos prometen una circulación constante de uno a otro. La teoría deja de ser autor de la tragedia y toma la posición de uno de sus personajes. Así, más oráculo de Apolo, aquella es ahora su palabra cumplida.

“...la tragedia sitúa de entrada al individuo en la encrucijada de la acción, frente a una decisión que le compromete por entero, pero esta ineluctable elección se opera en un mundo de fuerzas oscuras y ambiguas, un mundo dividido donde el derecho jamás está fijado, sino que se desplaza en el curso de la acción, "torna" y se transforma en su contrario." (27)

\section{Tragedia de la teoría.}

Acométase, sin embargo, a la Esfinge. La anterior condición deja todavía una ranura por la que entran las dudas. Esta siguiente y última es única, en cuanto que Freud no creyó necesario mencionarla nada más que a ella en el curso de su argumentación de 1900 .

"En apoyo de esta idea la Antigüedad nos ha legado una saga cuya eficacia total y universal sólo se comprende si es también universalmente válida nuestra hipótesis sobre la psicología infantil.” (28) 
Sólo siendo connatural el complejo a la vida humana tiene entidad teórica la proposición, la equiparación entre representaciones individuales y colectivas separadas en tantos aspectos, y sus anteriores. Y teniéndola no la tienen las críticas de Vernant a pesar de, como se ve, tenerla.

Aunque cómo comprender que pueda darse el caso de que tan breves apuntes encerraran verdaderamente todo el desarrollo anterior. Si se consiguiera, entonces, no sería más que junto a, y por, la misma causa que hace posible introducir a Freud dentro del texto de Sófocles en busca de una nueva interpretación con el tipo de consistencia que, no puede negar, exige la antropología a las suyas.

"Pues aunque un conocimiento esté enteramente de acuerdo con la forma lógica, es decir, aunque no se contradiga a sí mismo, puede seguir estando en contradicción con su objeto." (29)

No es difícil, si el modelo de comparación del fenómeno es el de las matemáticas. Si la demostración no es acertada y la proposición o el teorema sí resulta serlo no estamos sino ante un caso particular de uno de los fenómenos más frecuentes de esta ciencia. Lo mismo da que la demostración sea contradictoria o esté ausente, como en el caso de Fermat que enunció su famoso teorema sin demostrar, si la tesis se verifica, porque esa demostración es un puzzle que puede cualquiera recomponer; cuyas piezas no se salen del resto de teoremas demostrados y axiomas que conforman la matemática. Así que, puesto que la matemática del psicoanálisis que él mismo construyó es capaz de fraguar la demostración de esa asociación entre contenidos -conflicto y mito-, Freud, si se cumple este caso, sería

“...semejante a esos pilotos expertos o grandes médicos que ven de una sola ojeada hasta dónde puede llegar su arte, que toman inmediatamente partido sobre lo que es posible y lo que es imposible..." (30)

La importancia concedida a este conocimiento intuitivo mayor o menor que su declaración, que iguala a Freud y Fermat arriba, responde también a un principio extraído de la matemática freudiana -de especial significado en aquella primera época. Da pie, de paso, a una exposición sobre el interior del texto coherente con los más importantes supuestos enunciados por Anzieu y no incoherente con las observaciones de Vernant sobre su aplicación. No obstante, para ilustrarla, debe observarse a la inversa, tarea que queda al lector. Una paradoja de experiencia que a Freud gusta señalar.

“...(e) El hecho de que entre los histéricos uno encuentra a los seres humanos de más claro intelecto, voluntad más vigorosa, mayor carácter y espíritu crítico. En tales casos, esta última caracterización es correcta para el pensar despierto de estas personas; pero en sus estados hipnóticos son alienados, como todos 
nosotros lo somos en el sueño. Nuestras psicosis oníricas no influyen sobre nuestro estado de vigilia, mientras que los productos de los estados hipnoides penetran en la vida de vigilia como los fenómenos histéricos." (31)

\section{Peripecia.}

Porque negar que Edipo sepa y no sepa equivale a negar también que cumple y no cumple el oráculo, por el mero hecho de que hay una parte de él que no sabe, que no lo conoce. No se puede decir que cumple, debido sólo a sí mismo, el oráculo. Tampoco, sino sólo por mediación divina, conoce y, por ello, conociendo, desconoce y no cumpliendo el oráculo, lo cumple. Como en el oráculo se resume lo que no cumplirá, esto es, lo que cumplirá aquella parte que no cumple con su destino. Caracterización que también parece autorizar no sólo Freud sino el mismísimo Sófocles,

“CORIFEO.- ¡Desdichado por tu clarividencia, así como por tus sufrimientos!”

También la antropología declara sin reservas que en la conversación con Creonte nuestro personaje principal proyecta sus sentimientos. Que la envidia a los poderosos, en razón de su posición; el phtónos, que Edipo le atribuye no proviene de otro que de él. Esta admisión ya es suficiente como para convencerse de que no tienen sentido las dudas acerca de que el hecho de que Edipo pueda conocer y no conocer su destino, hacerlo y no hacerlo, dejarse guiar y no dejarse guiar por él, ambos grupos de categorías excluyentes que conviven al tiempo, juntas, todo el contenido del destino concentrado en $\phi^{6} \phi^{6} \phi$

Y sabe, quiera o no, en todo momento, el oráculo que le dictó Loxias, conoce, aunque no conozca, el explícito mensaje de Tiresias.

\section{Historicidad de la causa trágica.}

Entonces, una vez se admiten las condiciones anteriores, debe examinarse la hipótesis que usa la analogía del teorema de Fermat. Ya que se sabe que, contando la historia de la teoría de la tragedia, la teoría se convierte en tragedia y desaparecen los límites entre una y otra. Si la teoría responde la tragedia seguramente también lo hará.

Del mismo modo que sabe Edipo, sin saber, todo el tiempo; es decir, que sabe aunque lo que sabe no se le aparezca en toda su extensión, el resto de tragedias que no presentan la figura de Edipo, aunque ni lo hagan ni lo sepamos, la presentan. Lo mismo hay que decir para el resto de las versiones del mito de Edipo, aunque estén, por así decirlo, truncadas.

Lo que prueba "Edipo rey" es que no es "Edipo rey". Así como el oráculo está dicho sólo de una manera, en un momento como oráculo probable para Edipo pero desperdigado, ocurriendo en cada uno de los momentos de la pieza, la palabra 
del complejo no tiene que ser dicha para ocurrir ni ocurrir por ser dicha -aunque esté ocurriendo.

Ni está cerca, como Edipo si exigiese identidad, en el sentido de lo idéntico, ante la perspectiva de proyectarse en Creonte, ni lejos tampoco de esa figura, pues en cierto modo, cuando lo hace, en algo -y bien crucial- se le asemeja. Así, ni son iguales que "Edipo rey" ni distintos, sino exactamente distintos o imprecisamente iguales, como enseña Vernant. Como sin saberlo, sabiendo, dice Aristóteles:

“(E) empero, accidentes que pasen entre amigos -como cuando hermano mata a o está a punto de matar o hacer algo parecido con hermano, o hijo con padre, o madre con hijo, o hijo con madre- son puntualmente los que se deben buscar." (33)

Si se equipara humanidad e individualidad, contexto clínico y social, la condición de universalidad del complejo en clínica no implica la presentación en cada individualidad de ese conflicto; la enunciación efectivamente consciente, en cada uno y todos los pacientes, de ese conflicto tal como lo representa la teoría. La clínica admite una probabilidad de presentación, frente a la necesidad o supuesto cierto de presencia para todo sujeto. Esa misma probabilidad es la que se observa entre el espectro completo de las tragedias y versiones del mito, como si correspondieran a la narración de un solo sujeto. Presencia, se puede decir, en estructuras, sin presentación, en el resto de las tragedias, presencia más presentación incompleta, en el conjunto de las versiones del mito de Edipo, y presencia más presentación completa en "Edipo rey".

"El camino que parte de la construcción del analista debía culminar en el recuerdo del analizado; ahora bien, no siempre lleva tan lejos. Con harta frecuencia no consigue llevar al paciente hasta el recuerdo de lo reprimido (...). Bajo que condiciones aparece esto, y cómo es posible que un sustituto al parecer no integral produzca, no obstante, todo el efecto, he ahí materia de una investigación ulterior." (34)

\section{Mito-logos.}

A lo que parece esta tragedia no puede interpretarse separando continente de contenido, pues lo explícito y lo implícito son una misma y distinta cosa. El texto es un enigma.

Hay que dar la razón a Vernant cuando defiende que el texto ha de ser explicado desde su interior y hacia su interior. Y si Edipo, no hay problema en asumir que con Creonte, cómo no se identificará -léase id-entificar- con el pueblo de Tebas. (Pues la equiparación entre contexto clínico y social pareció resolver las contradicciones entre la argumentación vernantiana y la psicoanalítica y la confusión entre teoría y su objeto, en este caso, parecerá también resolverlas). 
La presentación de los elementos no es azarosa, a pesar de ser enigmática, y el primer personaje que aparece en el relato es, antes de Edipo, el pueblo suplicante azotado por la desgracia enviada por los dioses: la peste. La peste define a Edipo por transitividad. Si Tebas es peste y Edipo es Tebas; Edipo es peste. El examen no es este punto pues, sino el cómo y por qué de lo dicho.

El mismo Apolo se encarga de, no sólo presentar la peste, decir explícitamente lo que constituye su definición. No existe definición distinta de la peste y de Edipo y ella sólo es, respecto del pueblo, respecto de la relación que mantienen Tebas y Edipo un sustituto de su nombre. Pues Apolo, y es imposible quitar la razón al flechador, al dios -que siempre acierta-, identifica, en el oráculo que se manda recoger a Creonte, al asesino de Layo con aquélla, afirmando que una y otro son de la misma causa.

"La condición del hombre tiránico por sus pasiones, es, pues, la misma que la de un estado oprimido por un tirano..."

"Sí, las cosas pequeñas, como no ignoras, no son tales sino por comparación con las grandes, y todos esos males que digo, puestos en parangón con los que padece un estado oprimido por un tirano no pasan de ser bagatelas." [(9). 590].

\section{Apología de Sófocles.}

El mismo texto resuelve las dificultades que la antropología trataba de anclar al panorama social y el psicoanálisis al familiar -y el trágico al divino. Su interior, pues, recoge esos tres referentes, cuyo objetivo no es otro que desentrañar la naturaleza humana. Se muestra perfecto intérprete de las teorías que le suceden como piezas de su puzzle.

De este modo se presta la aparición en escena de la peste a equipararse al episodio de Creonte que también dice, más o menos crípticamente, lo mismo. La peste es perfectamente semejante al alma del rey porque la cualidad que se resalta es la que la define por su relación con Tebas, la desolación, el sufrimiento, etc. Sin embargo, la matriz de proyección es mayor, está más alejada que la creontínea del sujeto, hecho que hay que traducir en mayor ocultamiento en otro sentido, en el de referencia, por eso la identidad con ella está lejos y el episodio necesita la traducción directa del dios. El cambio de término de referencia, Tebas por Creonte, se transforma en el tipo de proyección que se encuentra en su episodio. El hecho a aislar es equivalente, en sus resultados, al principio de incertidumbre. Los distintos términos de referencia dan distintos resultados en su apariencia pero el mismo en esencia.

"¿...que llegase hasta a levantar la mano a su padre o a su madre, a sus amigos más antiguos y más necesarios, sin respeto a su edad, llegando incluso a querer rebajarlos y someterlos al objeto de sus amores, al cual habrá introducido en casa de sus propios padres?" (36) 
Por eso, dentro de esta perspectiva evolutiva, de evolución representativa, el episodio de aquel borracho cobra especial valor; resume perfectamente el texto. $\mathrm{Su}$ difusa intuición de antaño es la que Edipo alcanza a comprender y reconocer en el último momento del drama identificándola, sólo después de haber sido visto en el espejo del resto de referentes puestos en juego, con la verdadera definición de su alma. Ahora comprende su ardor desproporcionado. Todos los males y la ignorancia que lo acompaña y los provoca estaban en ese punto espiritual, equivalen a otra palabra que la que quería cuyo referente interior sólo tras todo el terremoto está claro para él.

“¡Oh Pólibo y Corinto y antigua casa paterna -sólo de nombre-, cómo me criasteis con apariencia de belleza, pero corrompido de males por dentro! Ahora soy considerado un infame y nacido de infames." (37)

“-Por lo demás, no hace falta que haya llegado al poder para que se de a conocer tal cual es; cuando todavía vive en condición privada, muestra ya su carácter." (38)

Desde el mismo corazón del mito la voz de Edipo resuena e ilustra la respuesta a una polémica que ni él mismo podría imaginar. A menos que el mito sea mayor y se conozca a sí mismo mejor que lo que imaginamos, imaginamos poder conocerlo, resolviéndose antes de haberse hecho problema o es, al modo matemático, en que sólo se distinguen por el nombre. El problema y la solución, también la matemática, están, en la encrucijada de Delfos.

“EDIPO.- ¡Oh hijos dignos de lástima! Venís a hablarme porque anheláis algo conocido y no ignorado por mí. Sé bien que todos estáis sufriendo y, al sufrir, no hay ninguno de vosotros que padezca tanto como yo. En efecto, vuestro dolor llega sólo a cada uno en sí mismo y a ningún otro, mientras que mi ánimo se duele, al tiempo, por la ciudad y por mí y por ti. De modo que no me despertáis de un sueño en el que estuviera sumido sino que estad seguros de que muchas lágrimas he derramado yo y muchos caminos he recorrido en el curso de mis pensamientos." (39) 


\section{BIBLIOGRAFÍA}

1. Sófocles. Edipo Rey. Madrid, Gredos, 2000. P. 775

2. Vernant, J. P. Mito y tragedia en la Grecia Clásica. Barcelona, Taurus, 1988. P. $94-95$

3. Id. p. 93

4. Id. p. 94

5. Id. p. 95

6. Ibíd.

7. Id. p. $98-99$

8. Ibíd

9. Id. p. 86

10. Id. p. 79

11. Id. p. 100

12. Id. p. $80-81$

13. Id. p. $79-80$

14. Id. p. 83

15. Ibid

16. Id. p. 81

17. Ibid

18. Id. p. 82

19. Ibid.

20. Freud, S. “Un caso de curación por hipnosis”. Ob. comp. Tomo I. Buenos Aires. Amorrortu, 1996.p.160

21. Vernant, J. P. Op. cit. p. 96

22. Sófocles. Op. cit. p. $1319-1320$

23. Freud.S.;Breuer,J.“Estudiossobrelahisteria”Ob.comp. TomoII. BuenosAires. Amorrortu, 1996.p.71-72

24. Vernant, P. Op. cit. p. 79

25. Freud, S. “Construcciones en psicoanálisis”. Ob. comp. Tomo III. Buenos Aires. Amorrortu, 1996.p. 271

26. Nietzsche, F. El nacimiento de la tragedia. Madrid. Edaf. 1998. p. 271.

27. Vernant, P. op. cit. p. 84

28. Freud. S. "La interpretación de los sueños” Ob. comp. Tomo IV. Buenos Aires. Amorrortu, 1996. p. 271.

29. kant, I. Crítica de la razón pura. Madrid. Alfaguara, 1978. p. 98

30. Platón. La república. México. Porrúa, 1998. p. 457

31. Freud, S. Breuer, J. Op. cit. p. 39

32. Sófocles. Op. cit. p. 1347

33. Aristóteles. Poética. Caracas. Univ. Central de Venezuela. 1977. p. 122.

34. Freud, S. Op. cit. en (25) p. 267

35. Platón. Op. cit. p. 590

36. Id. p. 589

37. Sófocles. Op. cit. p. 1394

38. Platón. Op. cit. p. 590

39. Sófocles, $O p$. cit. p. 600

*Alberto Herreros Salcedo

Licenciado en Psicología

Fase en investigación del doctorado: "Fundamentos y desarrollos psicoanáliticos"

Universidad Complutense de Madrid - e-mail: ajjjel@yahoo.es

Recibido: 26-03-02 